\title{
Cognitive processing of uncertainty: Its effect on pupillary dilation
}

\section{and preference ratings ${ }^{1}$}

\author{
ROBIN W. PRATT 2,3 \\ UNIVERSITY OF ILLINOIS
}

\begin{abstract}
The prediction of greater pupillary dilation as unpredictability (induced by random-turn shapes) increased was supported $(p<.001)$ in studies involving 40 young adults and 10 children. The postulated linearity of this increase found support, except in cases where apparent stimulus-selection strategies attenuated the dilation at higher levels of variability. Those Ss who did preference ratings concomitantly with the intake of visual unpredictability evidenced significantly greater dilation $(p<.001)$ at the time of reporting the rating. Both children and adults dilated significantly less to the shapes after prolonged experience with similar stimuli, indicating development of either ability to handle variability or to selectively filter input, but age was not a factor. The lack of any significant relationship between pupillary dilation and preference indicated the need for more definitive work in determining when these two indices profitably complement each other. Finally, adults dilated more to provocative auditory stimuli than to the visual shapes.
\end{abstract}

Cognitive uncertainty has been seen as a positive function of stimulus unpredictability and a negative function of the rules that have been developed to cognitively handle this environmental variation. In a series of studies (Munsinger, 1966; Munsinger \& Kessen,1964, 1966a,b,c; Munsinger, Kessen, \& Kessen, 1964) the viability of the concept of an upper limit on the ability to process new information from independent environmental events (Miller, 1956) was demonstrated and its influence shown to be a factor in determining preference for stimulus variation.

The Munsinger and Kessen work emphasizes the interactive nature of the environment with the state of the organism. The need for analysis of the organism's internal structure and for the concomitant redefinition of many of the tenets of traditional $S \cdot R$ psychology has been adequately portrayed by Pribram (1960, 1963), Hunt $(1963,1965)$, and Berlyne $(1960,1963)$. Indirect assessment of the cognitive structures can be done either by recording psychological behavior in response to environmental variation or by checking some physiological indicators of arousal or activation. The use of a coordinated approach comparing simultaneous output of the two kinds of indices has been found to help in defining psychological structures more insightfully (Kagan, 1967, 1968) and to aid in the development of better theoretical construction (Glanzer, 1967).

A promising approach to indexing mental state involves measuring various aspects of a complex of physiological changes, known collectively as the orienting reaction (OR), accompanying variation in stimulation (Berlyne, 1960, 1963; Razran, 1961). Sokolov (1963) has suggested that the magnitude of the OR is a positive function of the amount of mismatch between the present stimulus and a neural model based on past experience.

One aspect of the OR, pupillary dilation, has been recorded while Ss solved mental problems (Hess, 1965). Dilation increased until Ss indicated arriving at a solution. Beatty and Kahneman (1966) supported Hess's contention that pupillary dilation is an index of mental processing load with their finding that pupil size was linearly related to the amount of material stored by Ss for immediate recall or to its ease of being retrieved. Furthermore, they reported the dilation to follow, moment by moment, the amount of effort required by the memory and to diminish consistently as the material was overlearned. Kahneman and Beatty (1966) showed that pupillary dilation was positively related to the number of items being recalled or the difficulty thereof. Similarly, Kahneman and Beatty (1967) found that in a pitch discrimination task the magnitude of pupillary dilation upon presentation of the comparison tone increased with the difficulty of the discrimination. They interpreted this as evidence for the construct validity of pupillary dilation as an index of momentary state of mental effort

The present studies are an attempt to explore the index of pupillary dilation in reaction to random figures presumably differing in stimulus unpredictability. It is expected that pupillary dilation will increase positively with increases in the number of turns in the figures. The addition of the task of rating preferences for the various stimuli during Ss' processing of the visual input should increase the pupillary dilation, since the rating task is itself a cognitive process (cf. Simpson \& Paivio, 1966; Simpson, 1967).

Children and adults are to have their pupillary reactions compared both before and after extended experience with stimuli similar to those on which Ss are tested. Pupillary reactions after such experience are expected to be attenuated as a result of Ss' developing methods for handling the stimulus unpredictability. Since Munsinger and Kessen (1964) indicated that most adults have not developed abilities for handling random visual input with information content greater than channel capacity, adults may not react much differently from the children. Children, however, have been found to differ from adults in their handling of stimuli possessing high levels of variability (Munsinger \& Kessen, 1966c; Munsinger \& Weir, 1967), as they apparently sample only parts of the more unpredictable figures (Munsinger et al, 1964).

Ratings of preference for the stimuli are expected to be highest at or near the optimal level of uncertainty (cf. Munsinger \& Kessen, 1964). The relationship between pupillary dilation and ratings of preference is considered highly unpredictable since pupillary dilation is a momentary index of cognitive state, while a rating of preference is a judgment considered against several standards and probably has a time scale different from pupillary reactions. Accordingly, no consistent relationship between the two indices is expected.

Finally, it is expected that pupillary reactions will be consistently larger to selected segments presented auditorily than to the visual shapes because the content of the auditory stimuli is more varied and provocative. Through the use of the two quite different types of stimuli, it is hoped to compare purely information input to input possessing associational significance.

Subjects

\section{METHOD}

Forty adults ranging in age from almost 18 to 27 years volunteered to serve as Ss. All Ss were divided into four groups of 10 each by randomizing each block of four Ss 
equally into the four conditions. Ten children ranging from 7 to 9 years old served in the developmental sessions. All Ss had normal uncorrected vision, and none reported any difficulty with the visual arrangement.

\section{Apparatus}

The testing was performed in a plain and remote basement room. Ss were seated on a chair, adjustable to height, and moved up to the table containing the headrest. A foam-rubber chin rest and foam-rubber-padded adjustable head clamps held S's head in position. Heavily padded Permoflux PDR 10 earphones attenuated $35 \mathrm{~dB}$. To further mask noises from the projector and other sources, a tape recording of 40-dB narrow-band noise with a mean of $500 \mathrm{~Hz}$ (a rectangular distribution of 490 to $510 \mathrm{~Hz}$ ) was played through the earphones. Beck (1967), who found pupillary reactions to sounds, specifically scored the need for control of auditory variation from apparatus.

A Packard-Bell DX 920 TV camera with a Cannon TV C16 zoom lens opened to nearly $90 \mathrm{~mm}$ (full zoom) was focused on S's left eye from a distance of $1 \frac{1 / 2}{\text { in. A }}$ Conrac CEA 25 TV monitor, 525 line with 27-in. screen, displayed a normal black-andwhite image of S's left eye. The circuit included a Sony EV 200 videocorder which kept a record on 1 -in. videotape of S's pupillary responses.

A Bell and Howell 16-mm movie projector presented the random shapes to S. Sound film was used so that the section of the film on which sound was recorded gave an electronic signal at the beginning and at the end of each slide which was recorded on the videotape simultaneously with the visual image of the pupil for that slide. A switch enabled $E$ to record either the blips from the film or the tape recorder during the auditory segment.

A School Master 102 slide projector, which was on during the entire experiment, projected a blank image light onto the same screen on which the stimulus presentations were being shown. This projected light came from a slight angle with the beam from the movie projector and greatly decreased contrast effects of the black slides on the white background without eliminating the distinguishing properties of the figures.

Using the right eye only, Ss viewed the stimulus presentation through a ground-glass screen at the end of a white oblong wooden box with inside dimensions of $51 / 2 \times 4 \times 36$ in. The earphones and the proximity of both TV camera and box isolated Ss from distracting visual or auditory stimuli.

Since the major stimuli were visual, control of lighting effects was vital. Woodmansee (1966), in his criticisms of methodology in previous pupillometric studies specifically called for the control of illumination differences between and within slides. Since the illumination falling on the right eye of $S$ varied somewhat during the session, even after careful control in the making of the stimulus film and the use of the slide projector to eliminate sharp contrast, the left eye was illuminated to a greater degree than the right eye with a low-voltage incandescent bulb shielded from $S$ by ground glass to reduce glare. This light was placed right next to the underneath side of the zoom lens, about 4 in. from S's left eye. Grossman (1967) reported that exposure of one eye alone to bright light results in the equal constriction of both pupils, a phenomenon known as isocoria or the "consensual pupil reflex [Bartley, 1951, p. 981]." The end result was a luminance transmittance constant at $32.3 \mathrm{~mL}$ on the left eye and luminance transmittance on the right eye which varied from $4.3 \mathrm{~mL}$ (for each of the random shapes) to $6.5 \mathrm{~mL}$ (for each control slide). Preliminary study indicated that gradual variation of illumination on the right eye (2.2- $\mathrm{mL}$ increase or decrease from a base of 5.4) had no effect on the diameter of the left eye. The black-on-white slides presented a contrast of $6.5 \mathrm{~mL}$ for background areas to $3.2 \mathrm{~mL}$ for the darker figures. The width of the visual presentation subtended a visual angle of $8 \mathrm{deg} 44 \mathrm{~min}$; the height, a visual angle of $6 \mathrm{deg} 45 \mathrm{~min}$.

\section{Stimulus Materials}

Sixteen slides of those used by Munsinger and Kessen (1964) were selected for the stimulus film presented to Ss. All the slides had been selected from among those judged as not very meaningful in the associational sense (cf. Munsinger \& Kessen, 1964). Four levels of unpredictability were used, assumed to fall in equal logarithmic steps. There were four separate examples each of 5-, 10-, 20-, and 40-turn random figures in the film.

A $16 \cdot \mathrm{mm}$ movie film was made for the stimulus presentation, since in this way a blank control slide could be interspersed between random-shape slides without any break in lighting that is common with slide projectors. The 16 slides were arranged in four blocks of four each so that each level of unpredictability was represented once at each position within a block. A table of random numbers was used to decide the order of the four blocks. The first four slides were preliminary slides, shown merely to allow Ss to beeome familiar with seeing slides per se, to assure more complete adaptation to the lighting conditions, and to give those Ss who were to rate their preferences another chance to anchor their judgments. The preliminary slides were exposed for 3 sec each and were separated by a blank slide for $10 \mathrm{sec}$. The 12 experimental slides that followed were each exposed for $7 \mathrm{sec}$ and then followed by a control slide for 7 sec.

The auditory segment presented to the adult Ss consisted of excerpts from public media, records, and a few amateur performances. The excerpts included political statements (Ss were tested during the height of the 1968 presidential campaign), vibrant musical selections, and some jokes that were designed to arouse the purient interests. The selections varied in length from 3 to $15 \mathrm{sec}$, and most of them were separated from other excerpts by a silent period (lasting from 3 to $10 \mathrm{sec})$. The complete tapes lasted just over 5 min.

\section{Procedure}

All Ss were tested one at a time during the daytime and at least $1 \mathrm{~h}$ from any meal so that they were considered reasonably alert. In an unoccupied classroom, each $S$ received instructions leading him to believe that he was to participate in an experiment about paying attention to various random shapes. He was then shown an example of each level of unpredictability slides (slides not used in the stimulus film) by a slide projector. He was then informed briefly about the conditions that would face him in the basement. He was not told that pupillary reactions were the object of the study. Most questions were deferred to the actual testing room where they could be answered more meaningfully.

Those Ss who were to rate their preferences for the random shapes were instructed in the use of the 7-point rating scale immediately following the general instructions. They were informed that they were to rate each shape against figures of the type that had just been shown to them and that would be presented quickly at the beginning of the stimulus film. After being reminded that there were no wrong answers, Ss were asked to spread out their ratings, i.e., to use as much of the 7-point scale as possible.

Once in the basement testing room, Ss were given a brief explanation of the 
apparatus. In addition, each $S$ was given a quick preview of the timing of the film. He was told it was necessary for him to stay steady and to have his eyes open at all times.

The Ss were allowed $1 \mathrm{~min}$ to adapt to the lighting and the random noise. The videocorder then began recording the pupillary responses continuously. Ten seconds later the film was started. After viewing the film, adult $S$ s were given a brief rest and then replaced in the apparatus to listen to the tape of excerpts. The screen on which they focused showed a blank slide ( $6.5 \mathrm{~mL}$ throughout).

Study 1: Pupillary responses and verbal expressions of preference in adults. In the present investigations, four conditions were needed to adequately separate the effects of rating the slides from the effects of processing the unpredictability from the random shapes per se.

Condition A-The 10 adult $S s$ in this condition were asked to indicate their ratings orally to $\mathrm{E}$ during the presentation of each slide. With the $7-\sec$ presentation interval, Ss were able to make this decision and report it without rushing.

Condition B-The 10 adult $S s$ in this condition were asked to give their ratings of the slides to $\mathrm{E}$ in the interval after the slide had been presented and while the control slide was on the screen.

Condition $\mathrm{C}-\mathrm{The} 10$ adult $\mathrm{Ss}$ in this condition rated their preferences for the shapes in the classroom, not in the pupillometric apparatus. Each $\mathrm{S}$ was tested individually on the same 12 experimental figures as were in the film and in the same order. A slide projector showed them a slide for $7 \mathrm{sec}$, and they were asked to give it a rating within $7 \mathrm{sec}$ after the cessation of the slide or before the next slide appeared. $E$ recorded these ratings as in Conditions $A$ and B. Half of the Ss rated before and half rated after viewing the film in a randomly counterbalanced (by pairs) order.

Condition D-The 10 adult Ss were instructed and then taken to the pupillometer without mention of rating. After the normal acquaintance with the apparatus and the final instructions, they viewed the film and had their pupillary responses recorded.

Study 2: Experience and pupillary response. The experience session for $\mathrm{Ss}$ was patterned after Study VI in the Munsinger and Kessen (1964) monograph. One week to 10 days after their original testings, Ss from Condition D of Study 1 returned to the classroom in which they had been instructed the first time. These sessions were conducted in two groups with five Ss each. Ss were all seated within easy viewing distance of the screen on the front wall.
They were instructed in the proper manner for circling their preferences. Ss viewed 120 pairs of slides projected onto the screen in front of them for $10 \mathrm{sec}$ per pair. The time interval between presentations was about 2 sec. After 60 pairs had been presented, Ss were given a 10 -min break.

A complete paired-comparison design following the order procedures of Ross (1934) was used. Ross's procedures allow for optimal control of time, space, fatigue, and transfer errors (Munsinger \& Kessen, 1964). The 17 slides used included four examples each of 5-, 10, 20, and 40-random-turn shapes and one 6-turn figure. The 12 slides that had been used in the stimulus film were turned upside down and backwards in these presentations. Comparisons involving a shape of one level of unpredictability with another of that same level were deleted, leaving the 12 item pairs. In the 240 total slides presented, there were 55 examples each of $5-, 10-, 20-$ and 40-turn shapes and 20 appearances of the 6-turn figure.

The retesting of Ss used in the experience session was delayed from 2 to 6 days after the extended experience. Ss returning for the final retest were reminded of the conditions of the pupillometric apparatus and then were taken down to the experimental room. There they were secured in the apparatus and were shown the film they had seen in the original session under the same conditions. Again, these Ss were not required to rate any of the shapes. Ss were retested at the same time of day as they had been tested before.

Study 3: Children's pupillary responses to varying degrees of unpredictability. The 10 children who served as Ss, with permission from parents, for the developmental part of the study were run as were the adult $S s$ in Condition D of Study 1 (visual stimuli only).

Study 4: Experience and pupillary responses in children. The experience sessions for the children of Study 3 were run in the same manner as the experience sessions for the adults.

\section{Measurement procedure}

The second-by-second recording of the pupillary diameter for each $S$ was accomplished by replaying the videotape and stopping it at 1-sec intervals. For later analyses, four specific time intervals were analyzed for each slide. The BASE was calculated as the mean of the diameter at the onset of the slide presentation and the two scores immediately prior to the onset. The mean of the two readings at 2 and $3 \mathrm{sec}$ after the onset of the slide was designated as PRIME. The mean of the three scores 5, 6, and $7 \mathrm{sec}$ after the beginning of the slide was called MIX (since the conditions were doing different things during this time). The scores 1 and $2 \mathrm{sec}$ after the beginning of the control slides were averaged to form BLANK.

The pupil diameters used in the analyses were taken from the magnified image on the TV monitor. The scale was $1 \mathrm{~mm}=12.2$ projected millimeters. Therefore, the grand mean pupil diameter of $48.77 \mathrm{~mm}$ translated to $4 \mathrm{~mm}$ actual size.

\section{RESULTS AND DISCUSSION}

Table 1 presents the mean pupillary dilations (PRIME-BASE) and 95\% confidence intervals for the Mean Dilations by Levels of Unpredictability for each of the four adult conditions. It is readily apparent that pupillary dilation increased monotonically with unpredictability. Condition $A$ adults seemed to have evidenced the greatest dilation responses due probably to their being the only group performing the preference rating task during the viewing of the slide itself. The analysis of variance of the data summarized in Table 1 indicated that the groups differed significantly in their mean pupillary dilations, $F(3,36)=10.60$, $\mathrm{p}<.001$, thus supporting the observed higher performance by Condition A Ss. In addition, the dilation to the different levels of unpredictability appeared to differ quite significantly, $F(3,108)=33.56, p<.001)$.

Separate Treatment by Ss analyses of

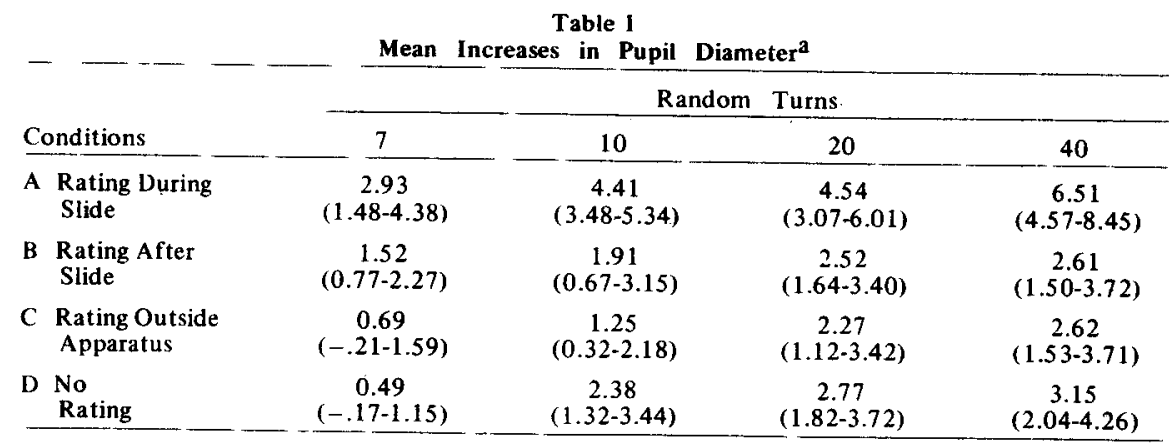

a Prime Score - Base Score: The values under each mean are the $95 \%$ confidence intervals for that mean. The diameters used were measured off the video monitor. 


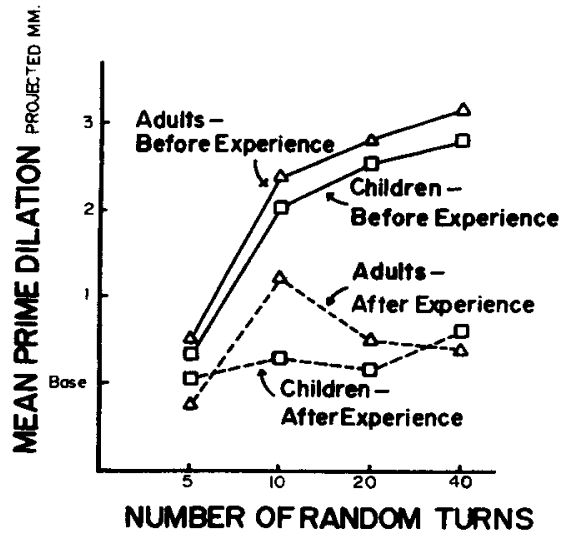

Fig. 1. Comparison of mean increases in pupillary diameter in children and adults.

variance for Conditions $A-D$ indicated a significant levels effect for each condition $(\mathrm{F}=12.92, \mathrm{p}<.001 ; \mathrm{F}=3.31, \mathrm{p}<.05 ;$ $\mathrm{F}=8.06, \mathrm{p}<.001 ; \mathrm{F}=12.46, \mathrm{p}<.001$, respectively; all with $3,27 \mathrm{df}$ ). Trend analyses showed that the assumption of a linear increase in mean dilation as unpredictability increased could not be rejected for the three conditions $(\mathrm{A}, \mathrm{B}, \mathrm{C})$ in which $S s$ did ratings of preference $(F=1.52, \quad p>.20 ; \quad F=0.31, \quad p>.50 ;$ $\mathrm{F}=0.40, \mathrm{p}>.50$, respectively; all with $2,27 \mathrm{df}$ ). For Condition D adults, the linearity of trend was rejected, $F(2,27)=4.47, p<.025)$. It appeared that the rejection of linearity in this condition was due to a leveling off of the increase in pupillary dilation at upper levels of variability. It is possible that those $S s$ who were not held to the viewing tasks by the rating performance did not always try to completely register all of the information in those shapes with high unpredictability. Any attempts at such stimulus sampling would have attenuated the linearity of the relationship between dilation and unpredictability.

Figure 1 depicts the comparison of the pupillary reactions for children and the comparable adult condition (D), both before and after experience. The pattern of means revealed a striking similarity between the two age groups as would have been predicted by following strictly the initial assumptions of Munsinger and Kessen (1964). Many of the studies by Munsinger et al that have shown differences in the way adults and children handle variability have had exposure times as a variable or have focused upon the effects of symmetry, neither factor of which was studied in the present research. As for the adult conditions, a Treatment by Ss analysis of variance was run on the dilation responses of the children, yielding a significant levels effect,
$F(3,27)=18.71, p<.001$, but the assumption of linearity was rejected, $F(2,27)=3.93, p<.05$. An apparent increase in the variability of responses to the 40-turn figures again reduced the trend toward linearity.

Table 2 presents the analysis of variance of the mean responses summarized in Fig. 1. As expected, the age effect was not significant, and age did not interact significantly with any other variable. Both the variables of experience and levels of unpredictability were highly significant. Surprisingly, the Experience by Levels interaction was also highly significant. Statistically, this interaction was due to a greater drop in pupillary dilation to the 20 and 40-turn figures than to the 5- and 10-turn figures.

To summarize quickly the results of the investigations on the role of experience in handling random shapes, the data apparently indicated that through the experience Ss gained some knowledge of the shapes used in the research being reported. This familiarity either: (1) enabled Ss to more easily handle stimulus unpredictability, (2) led them to almost totally disregard the shapes when repeated, or (3) enabled them to rapidly recognize those shapes containing unpredictability commensurate with their current abilities and to selectively filter the remaining ones. Future research can answer the question about the familiarity of the specific individual shapes by conducting another group of $\mathrm{Ss}$ as in Condition D, with the exception of using a stimulus film of similar proportions but containing new examples of the various levels of variability. In addition to comparing such results with the present ones, Ss should be checked on their ability to recall or recognize the shapes they had been viewing. In this manner some independent evidence may be gleaned concerning Ss' true attention to the stimuli. Such evidence may be helpful in understanding individual differences which may have caused the rejection of linearity with those Ss not doing ratings. It is seriously suggested that research check the possibility that, for many Ss, experience allows them to easily categorize inputs so that they do not have to truly process them. This tendency, supported from anecdotal evidence, is in contrast to optimal development of new sensitivities (Pribram, 1963) to higher-order variables (Gibson, 1966).

There were two time intervals specifically relevant to the rating function. Condition A Ss usually rated during the final seconds of the exposure of the slide (MIX), while Condition B Ss did their rating during the first 1 or $2 \mathrm{sec}$ of the blank slide (BLANK) following a figure. Upon analyzing the differences between the MIX and the BASE scores, the expected greater scores for the Condition A Ss led to a significant effect, $F(3,36)=17.75, p<.001$. The difference between BLANK and BASE scores yielded another significant conditions effect, $F(3,36)=41.03, p<.001$. This latter finding was the result of the greater pupillary diameters for Condition B Ss, who were the only Ss having dilation responses instead of a dimunition of dilation responses from the slides during the beginning seconds of the control slides. Taken together, these results strongly indicate that rating done while processing information adds significantly to the dilation. Added to the findings of Simpson and Paivio (1966) and Simpson (1967), such findings score the need to isolate any variable related to tasks concomitant with the primary one in pupillometric research.

The results just reported, when combined with the earlier findings, lend significance to the picture of the pupillary response gleaned from a second-by-second analysis of the mean responses by conditions. In general, diameters stabilized

Table 2

Analysis of Variance of Increases in Pupil Diameters ${ }^{a}$ (Adults and Children)

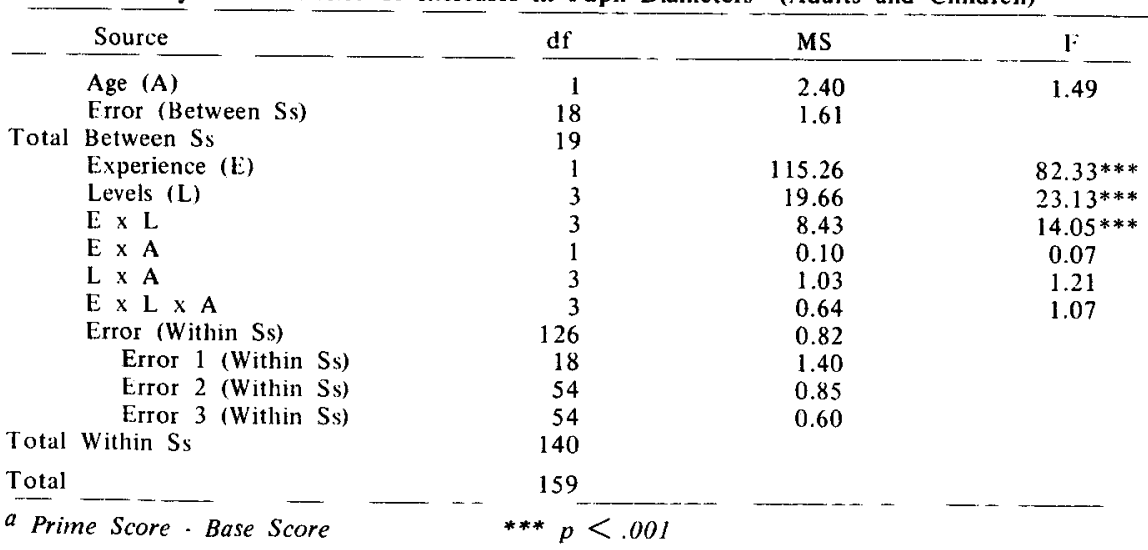


Table 3

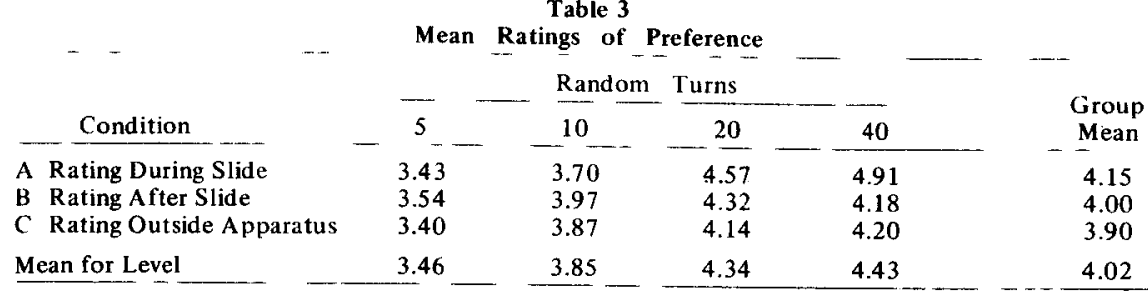

during blank slides, increasing when a new shape appeared and/or when $S$ s were rating preferences.

The 56 scores for each of three blocks of four slides were averaged and analyzed to check for the predicted decrease in baseline with time in the experiment (Woodmansee, 1966). There were no significant differences between conditions, $F(3,36)=1.01, p>.25$, but the drop across blocks was highly significant, $F(2,72)=52.92, \quad p<.001$. Since the decrements were not linear in Conditions $A$ and $D$, the decisions to randomize order of presentation of the different levels of unpredictability and to use difference scores (e.g., PRIME-BASE) in most analyses were supported.

A somewhat surprising finding is presented in Table 3 . Instead of demonstrating the expected nonmonotonic relationship between unpredictability and preference ratings, the mean ratings indicated a fairly stable positive monotonic trend (high ratings indicated high preference). An analysis of variance supported the conclusion of significant differences in ratings by levels, $F(3,81)=4.46, p<.01$, but it found no significant differences among the conditions, $F(2,27)=1.33, p>.25$.

One may only speculate why these data did not show the inverted-U-shaped eurve so often found by Munsinger and Kessen. Munsinger and Kessen (1966c) concluded that their studies had "reinforced our Table 4

Mean Proportion Increases in Pupil Diameter ${ }^{\mathfrak{a}}$

$$
\text { Visual Audio }
$$
PRIME-BASL: AUDHD-AUDBS

\begin{tabular}{lcc}
$\begin{array}{l}\text { Condition } \\
\text { A Rating }\end{array}$ & BASE & AUDBS \\
$\begin{array}{l}\text { During } \\
\text { Slide }\end{array}$ & $(103-149)$ & $(.111-201)$ \\
B Rating & & 156 \\
$\quad \begin{array}{l}\text { After } \\
\text { Slide }\end{array}$ & $(.029-.075)$ & $(.098-.144)$ \\
C Rating & & .121 \\
$\begin{array}{l}\text { Outside } \\
\text { Apparatus }\end{array}$ & $(.028-.074)$ & $(.112-.202)$ \\
D $\begin{array}{l}\text { No } \\
\text { Rating }\end{array}$ & $(.040-.086)$ & $(.123-.169)$ \\
\hline
\end{tabular}

a The values in parenthese's ander cach mean proportion are the $95 \%$ confidence intervals for that incan proportion. suspicions that variability is handled in two different ways depending on task and time requirements [p. 47]." It may be that the rating task, coupled with the need for remembering the proper time in which to orally report the ratings, added to the impact of the visual information, forcing some $S s$ in Conditions $A$ and $B$ to adopt a partial stimulus-sampling strategy (cf. Munsinger, 1966). A second alternative is that Ss used in these studies were different from those used previously on some dimension relevant to handling variability. Finally, it is possible that reporting the ratings orally to $\mathrm{E}$ may have changed such reports. Ss who were concerned about the image their responses might create could have been persuaded to increase their ratings for shapes of high variability in order to indicate that they could handle such unpredictability. If the latter instance were indeed the case, it seems that the index of pupillary dilation has an advantage over the index of expressed preference, at least in situations where the development of cognitive structure through experience is being studied. Apparently, the advantage of using pupillary dilation results from its being less under the control of Ss' social expectations.

In the interest of coordinated R.R research, the relationships between prime pupillary dilation and preference ratings were checked for each level of unpredictability. The correlation coefficients for the 5-, 10-, 20-, and 40-turn figures (respectively) were as follows: for Condition $\mathrm{A},-.08, .14, .24$, .21 ; for Condition $\mathrm{B}, .02,-.23, .50, .37$; for Condition $\mathrm{C}, .08, .01,-.17,-.37$. None of these values was significant (critical value $r=.63$, one-tailed test), and there was no evidence of a curvilinear relationship. Nonetheless, the results were in line with the present researcher's contention that the indices of expression of preference and pupillary dilation are evidences of processes which only partially overlap. More definitive work, involving assessment of individual differences in cognitive hierarchical patterns and precise control of the timing of recording of the indices, is suggested as necessary in uncovering informative relationships between dilation and expressions of preference. The results are presently interpreted as meaning that Ss' evaluations of their liking for a situation should not necessarily be considered as indicative of their state of cognitive functioning.

Seven blank segments and 10 segments of excerpts, ranging from 3 to $5 \mathrm{sec}$ in length, were originally checked for the greatest and the least pupillary diameter during the interval in order to observe the course of the reactions to the auditory stimuli. There was clear evidence that each new excerpt induced pupillary dilation. The pupillary responses to five segments, selected by pilot Ss as the most vivid of the tape, were averaged (high points) to form auditory high dilation (AUDHD). The four silent periods nearest them had their high scores averaged to give auditory base (AUDBS). All of these time periods were during the last of the tape. Table 4 presents the means and $95 \%$ confidence in tervals for the proportion AUDHD increased over AUDBS, and it compares them to the proportion PRIME increased over BASE to the 40-turn visual figures. It is apparent that only in Condition A, where the effects of ratings combined with the impact of the visual information, did the dilation responses compare with the responses to the provocative auditory stimuli. This was apparently due to the combination of novelty, ribaldry, and variability of type of input that the auditory tape possessed. The larger dilations to the auditory segments indicated that any lack of linearity in earlier analyses was not due to a ceiling having been reached in the pupillary dilation response.

\section{A FINAL FINDING}

There still remained the question of how the pupillary dilation to a truly exciting, unexpected stimulus would compare to those resulting from the visual and auditory stimuli used in the studies just reported. Taking advantage of the remote area and the psychological isolation of $S, E$ perceived an unusual opportunity to lead a $S$ to believe that she was being amorously approached by $E$ when, in fact, it was by her own husband.

After a female $\mathbf{S}$ was conducted through the last session in the pupillometric apparatus, $E$ asked $S$ if she would return to the apparatus for about $1 \mathrm{~min}$ so that he could study her eye movements when there was no visual stimulus present. In her visual and auditory (masking noise) isolation, $S$ had no idea that her husband had slipped into the room behind her. The $E$ left the room. The S's husband was instructed to make an amorous advance toward his unsuspecting wife. Shortly thereafter, E heard S exclaim, "Are you kidding me?"

Prior to her husband's appearance, S's pupillary diameter had stabilized at 
$50-52 \mathrm{~mm}$. As she began to realize what was happening, her pupil started to dilate dramatically. Within $2 \mathrm{sec}$ her diameter had reached a high of $75 \mathrm{~mm}$ and $9 \mathrm{sec}$ after the beginning of the reaction the diameter was still at $71 \mathrm{~mm}$ when she left the apparatus.

It is felt that this demonstration of prolonged dilation of nearly $50 \%$ (albeit fragmentary evidence) can serve as some sort of standard with which to compare the magnitude of other pupillary dilations.

\section{CONCLUSIONS}

The studies presented have supported the idea that pupillary dilation is an index of cognitive uncertainty for groups. Both the increase in unpredictability of the stimuli and the addition of the cognitive task of rating produced significant increases in dilation. By using the suggested indices of recall of stimuli along with pupillary reactions, the convergent information should enable individual capabilities and preferences to be better assessed.

Furthermore, the nonconfirmation of the inverted-U-shaped relationship between preference and unpredictability suggests modification of the basic tenets of the Munsinger and Kessen position, as they have been doing. In addition, the index of verbal expression of preference is shown to have questionable generalizability.

\section{REFERENCES}

BARTLEY, S. H. The psychophysiology of vision. In S. S. Stevens (Ed.), Handbook of experimental psychology. New York: Wiley, 1951. Pp. 921-984.

BEATTY, J., \& KAHNEMAN, D. Pupillary changes in two memory tasks. Psychonomic Science, 1966, 5, 371-372.

BECK, B. B. The effects of the rate and intensity of auditory click stimulation of pupil size. Paper presented at the meeting of the American Psychological Association, Washington, D.C., September 1967.

BERLYNE, D. F. Conflict, arousal, and curiosity. New York. McGraw-Hill, 1960.

BFRLYNE, D. E. Motivational problems raised by exploratory and epistemic behavior. In S.
Koch (Ed.), Psychology: A study of a science. Vol. 5. New York: McGraw-Hill, 1963. Pp. 284-364.

GIBSON, J. J. The senses considered as perceptual systems. Boston: Hough ton Mifflin, 1966.

GLANZER, M. Individual performance, $R-\mathbf{R}$ theory and perception. In R. M. Gagne (Ed.), Learning and individual differences. Columbus, Ohio: Merrill, 1967. Pp. 000-000.

GROSSMAN, S. P. A textbook of physiological psychology. New York: Wiley, 1967.

HESS, E. H. Attitude and pupil size. Scientific American, 1965, 212, 46-54.

HUNT, J. McV. Motivation inherent in information processing and action. In $\mathrm{O}$. $J$. Harvey (Ed.), Motiration and social interaction: Cognitive determinants. New York: Ronald Press, 1963. Pp. 35-94.

HUNT, J. McV. Intrinsic motivation. In D. Levine (Ed.), Nebraska symposium on motivation: 1965. Lincoln: University of Nebraska Press, 1965. Pp. 189-282.

KAGAN, J. On the need for relativism. American Psychologist, 1967, 22, 131-142.

KAGAN, J. Continuity and change in the first year of life. Presidential Address, Division 7, at the meeting of American Psychological Association, San Francisco, September 1968.

KAHNEMAN, D., \& BEATTY, J. Pupil diameter and load on memory. Science, 1966, 157, 218-219.

KAhNEMAN, D., \& BEATTY, J. Pupillary responses in a pitch-discrimination task. Perception \& Psychophysics, 1967, 2, 101-105.

MILLER, G. A. The magical number seven, plus or minus two: Some limits on our capacity for processing information. Psychological Review, 1956, 63, 81-97.

MUNSINGER, H. Multivariate analysis of preference for variability. Journal of Experimental Psychology, 1966, 71, 889-895.

MUNSINGER, H., \& KESSEN, W. Uncertainty, structure, and preference. Psychological Monographs, 1964, 78 (Whole No. 596), 1-24.

MUNSINGER, H., \& KESSEN, W. Stimulus variability and cognitive change. Psychological Review, 1966a, 73, 164-178.

MUNSINGER, H., \& KESSEN, W. Preference and recall of stimulus variability. Journal of Experimental Psychology, 1966b, 72, 311-312.

MUNSINGER, H., \& KESSEN, W. Structure, variability, and development. Journal of Experimental Child Psychology, 1966c, 4, $20-49$.

MUNSINGER, H., KESSEN, W., \& KESSEN, M. L. Age and uncertainty: Developmental variation in preference for variability. Journal of Experimental Child Psychology, 1964, 1, 1-15.

MUNSINGER, H., \& WEIR, M. W. Infant's and young children's preference for complexity. Journal of Experimental Child Psychology, $1967,5,69-73$.

PRIBRAM, K. H. A review of theory in physiological psychology. Annual Review of Psychology, 1960, 11, 1-40.

PRIBRAM, K. H. Reinforcement revisited A structural view. In M. R. Jones (Ed.), Nebraska symposium on motivation: 1963. Lincoln: University of Nebraska Press, 1963. Pp. 113-159.

RAZRAN, G. The observable unconscious and the inferable conscious in current Soviet psychophysiology: Interoceptive conditioning, semantic conditioning, and the orienting reflex. Psychological Review, 1961, 68, 81-147.

ROSS, R. T. Optimum orders for the presentation of pairs in the method of paired comparisons. Journal of Educational Psychology, 1934, 25, 375-382.

SIMPSON, H. M. Pupillary activity during imagery tasks. Paper presented at the meeting of the American Psychological Association, Washington, D.C., September 1967.

SIMPSON, H., \& PAIVIO, A. Changes in pupil size during an imagery task without motor response involvement. Psychonomic Science, $1966,5,405-406$.

SOKOLOV, E. N. Perception and the conditioned reflex. New York: Macmillan, 1963.

WOODMANSEE, J. J. Methodological problems in pupillographic experiments. Proceedings of the 75th Annual Convention of the American Psychological Association, 1966, 13-134.

\section{NOTES}

1. Submitted in partial fulfillment of the requirements for the $\mathrm{PhD}$ degree at the University of Illinois, 1969. The author expresses his gratitude to Dr. J. McV. Hunt and Dr. Harold Hake for their direction and encouragement. The research was performed while the author was at the University of Redlands and was supported by a grant from its faculty research committee.

2. Now at the University of North Carolina, Greensboro, North Carolina 27412.

(Accepted for publication November 26, 1969.) 